\title{
Bioactive new bitter-tasting $p$-hydroxystyrene glycoside and other constituents from the fern Elaphoglossum spathulatum
}

\author{
Cecilia Socolsky, ${ }^{a}$ Analía Salvatore, ${ }^{b}$ Yoshinori Asakawa, ${ }^{c}$ and Alicia Bardón ${ }^{a_{*}}$ \\ ${ }^{a}$ Instituto de Química Orgánica, Facultad de Bioquímica, Química y Farmacia, Universidad \\ Nacional de Tucumán, Ayacucho 471, Tucumán 4000, Argentina, Tel: +54-381-4247752, Fax: \\ +54-381-4248025, ${ }^{b}$ Estación Experimental Agroindustrial Obispo Colombres, Av. William \\ Cross 3150, Tucumán, Argentina, ${ }^{c}$ Faculty of Pharmaceutical Sciences, Tokushima Bunri \\ University, Yamashiro-cho, Tokushima 770-8514, Japan \\ E-mail: alisan@fbqf.unt.edu.ar
}

Dedicated to Dr. Edmundo A. Rúveda and Dr. Roberto A. Rossi

(received 29 Aug 03; accepted 27 Sep 03; published on the web 02 Oct 03)

\begin{abstract}
Two bitter-tasting compounds were isolated from an Argentine collection of Elaphoglossum spathulatum, a new p-hydroxystyrene glycoside that we named elaphoside-A, and naringin. Structure elucidation of the new compound was carried out on the basis of extensive twodimensional $600 \mathrm{MHz}$ NMR analyses, as well as high resolution-mass spectrometry and chemical degradation and derivatization. Moreover, we report herein the isolation of the hopanoid diploptene, stigmasterol, $\beta$-sitosterol, ergost-5-en-3-ol, phytol, aspidinol, desaspidinol, vitamin E, neophytadiene, 1-(2,4,6-trihydroxyphenyl)-2-pentanone, and 6,10,14-trimethyl-2pentadecanone. In addition, we evaluated the alimentary and ovipositional response of Ceratitis capitata to the extracts and pure compounds of E. spathulatum. The new styrene glycoside produced severe disturbance in the ovipositional behavior of this pest insect.
\end{abstract}

Keywords: Elaphoglossum spathulatum, ferns, p-hydroxystyrene glycosides, bitter-tasting compounds, insect oviposition-deterrent

\section{Introduction}

The chemistry of the around 3000 species of ferns (pteridophytes) growing in Central and South America has been scarcely investigated. The genus Elaphoglossum Schott ${ }^{1}$ is widely distributed in these regions and some of its species are endemic and cover humid rocky walls in the Northwest of Argentina. 
Many fern constituents display various types of bioactivities. Aromatic compounds, glycosides and $\alpha$ - and $\gamma$-pyrones are responsible for the anthelmintic, antibacterial, mutagenic and antifeedant to insects effects observed. ${ }^{2}$ In the past, little attention has been paid to the glycoside constituents of pteridophytes though, from some species of this plant family, bitter and pungent substances have been isolated. ${ }^{3,4}$ Because bitter and hot-tasting plant constituents have proved to be active in bioassays, ${ }^{5,6}$ we decided to study the glycoside constituents of the bitter tasting fern E. spathulatum (Bory) Moore. This is the first description of the chemistry of the genus Elaphoglossum.

Here we report on the identification of the hopanoid diploptene, stigmasterol, $\beta$-sitosterol, ergost-5-en-3-ol, phytol, aspidinol, desaspidinol, vitamin E, neophytadiene, methyl arachidonate, 1-(2,4,6-trihydroxyphenyl)-2-pentanone, and 6,10,14-trimethyl-2-pentadecanone from the ether extract, as well as the new glycosides elaphoside-A and the well-known bitter substance naringin from the methanol extract.

We also report on the effects exerted by extracts and bitter-tasting compounds on the feeding and oviposition behavior of the fruit fly Ceratitis capitata Wiedemann.<smiles>[R]c1c(OC)cc(O)c(C(=O)CCC)c1O</smiles>

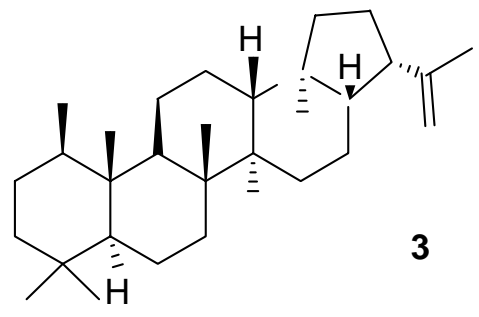

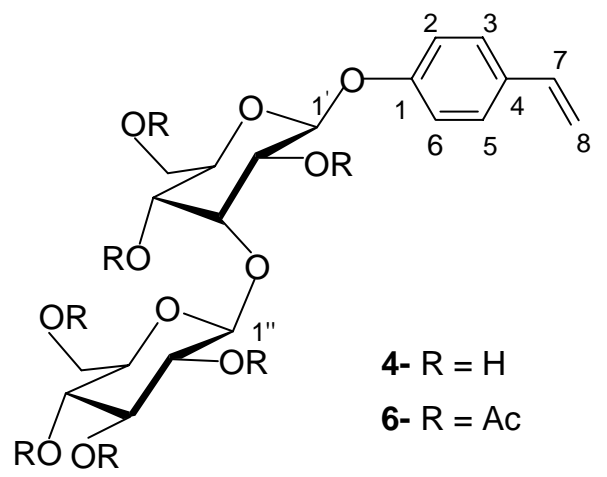

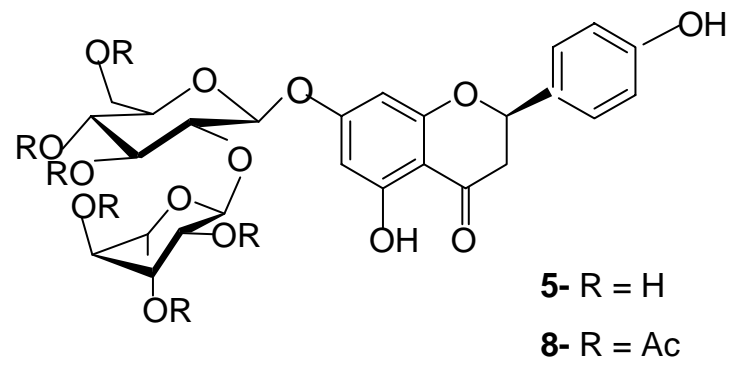<smiles>COC(C)c1ccc(O)cc1</smiles><smiles>C=Cc1ccc(O)cc1</smiles><smiles>O=C1C[C@H](c2ccc(O)cc2)Oc2cc(O)cc(O)c21</smiles> 


\section{Results and Discussion}

The air-dried sterile fronds were ground and extracted with diethyl ether and then methanol. The diethyl ether extract was analyzed by GC-MS to detect the common plant constituents $\beta$ sitosterol, stigmasterol, stigmast-5-en-3-ol, ergost-5-en-3-ol, stigmast-4-en-3-one, phytol, neophytadiene, vitamin E, methyl arachidonate, 6,10,14-trimethyl-2-pentadecanone and 1-(2,4,6trihydroxyphenyl)-2-pentanone. Three compounds, characteristic of ferns, were also detected, aspidinol (1), desaspidinol (2) and the hopanoid diploptene (3). Crystalline diploptene was further isolated from the ether extract employing chromatographic methods, and identified by its melting point, $[\alpha]_{\mathrm{D}}$, and spectroscopic features, in comparison with available data in the literature. ${ }^{7}$ It is important to point out that hopanoids are a group of pentacyclic triterpenoids only found in ferns, bryophytes, and bacteria ${ }^{6}$. Aspidinol and desaspidinol seem to be responsible for the anthelmintic effects detected in extracts from various species of ferns of the genus Dryopterys. ${ }^{2}$

The crude methanol extract was repeatedly chromatographed on silica gel and Sephadex LH20, to yield two bitter glycosides, the new elaphoside-A (4), and the known naringin (5) a flavanone neohesperidoside frequently found in citrus.

The FT-IR spectrum of elaphoside-A (4) showed a broad absorption at $3338 \mathrm{~cm}^{-1}$ due to the $\mathrm{O}-\mathrm{H}$ stretching, a $\mathrm{C}=\mathrm{C}$ band at $1628 \mathrm{~cm}^{-1}$ as well as two intense $\mathrm{C}-\mathrm{O}$ bands at 1080 and 1044 $\mathrm{cm}^{-1}$. The positive HR-FAB-MS spectrum of $\mathbf{4}$ gave a quasimolecular ion peak $[\mathrm{M}+\mathrm{Na}]^{+}$at $\mathrm{m} / \mathrm{z}$ : 467.1538 , consistent with the molecular formula $\mathrm{C}_{20} \mathrm{H}_{28} \mathrm{O}_{11}$, which accounts for seven degrees of unsaturation. The UV absorption pattern indicated the presence of a $p$-O-substituted styrene residue as has been reported for ptelatosides (styrene glycosides) isolated from the fern Pteridium aquilinum var. latiusculum. ${ }^{2}$ The $600 \mathrm{MHz}{ }^{1} \mathrm{H}-\mathrm{NMR}$ spectrum displayed two doublets at $\delta 7.35$ and $7.04(J=8.4 \mathrm{~Hz})$ consistent with the presence of four aromatic protons on a $p$ disubstituted benzene ring, as well as evidence for a monosubstituted double bond attached to a benzene ring: three signals at $\delta 6.66\left(d d, J_{\text {cis }}=10.8 \mathrm{~Hz}, J_{\text {trans }}=17.4 \mathrm{~Hz}\right), 5.64\left(d d, J_{\text {trans }}=17.4\right.$ $\left.\mathrm{Hz}, J_{\text {gem }}=0.9 \mathrm{~Hz}\right)$ and $5.11\left(d d, J_{c i s}=10.8 \mathrm{~Hz}, J_{\text {gem }}=0.9 \mathrm{~Hz}\right)$. The HMQC $\left({ }^{1} \mathrm{H}-{ }^{13} \mathrm{C}\right.$ correlation $)$ provided evidence for seven oxygenated methines and two oxygenated methylenes. The presence of a sugar moiety was clear by the signals between $\delta 3.3$ and $5.2 \mathrm{ppm}$ in the ${ }^{1} \mathrm{H}$ spectrum as well as the ${ }^{13} \mathrm{C}$ signals between $\delta 68$ and $106 \mathrm{ppm}$, two anomeric $\mathrm{C}$ being detected. Correlations were found between $\mathrm{C}-1$ of the styrene moiety $(\delta 158.8)$ and the anomeric proton of allose $(\delta 5.19, d, J$ $=7.8 \mathrm{~Hz})$ and between $\mathrm{C}-3$ of allose $(\delta 83.9)$ and the anomeric proton of glucose $(\delta 4.53, d, J=$ $7.8 \mathrm{~Hz}$ ) in the heteronuclear multiple bond correlation spectrum (HMBC) of 4. NOESY cross peaks were observed indicating a space proximity of aromatic protons $(\delta 7.4, d, J=8.4 \mathrm{~Hz})$ and the anomeric proton of allose as well as the $\mathrm{H}-3$ of allose $(\delta 4.31, t, J=3 \mathrm{~Hz})$ and the anomeric $\mathrm{H}$ of glucose. The mentioned evidence revealed the location of the sugar and the nature of the disaccaride. Acetylation of $\mathbf{4}$ gave the heptaacetylated derivative (6). Configurations of the sugar moieties at the anomeric protons were determined to be $\beta$-based on the coupling constants of the anomeric protons $\left(J_{1^{\prime}, 2},=J_{1^{\prime}, 2^{\prime},}=7.8 \mathrm{~Hz}\right)$ in $\mathbf{4}$ and $\mathbf{6}$. Acidic hydrolysis of $\mathbf{4}$ afforded glucose, 
allose and $p$-hydroxystyrene. HPLC analysis of sugars employing a chiral detector provided their absolute configurations. Further evidence was accomplished by methanolysis followed by acetylation of 4 that gave a mixture of methyl-2,3,4,6-tetra-O-acetyl- $\beta$-D-allopyranoside, methyl-2,3,4,6-tetra- $O$-acetyl- $\alpha$-D-glucopyranoside, and the methanol adduct of the aglycone $p$ hydroxystyrene $(7)^{8}$. Thus the structure of 4 is represented as $p$-hydroxystyrene $1-O-[\beta$-Dglucopyranosyl-( $(1 \rightarrow 3)-\beta$-D-allopyranoside].

Identification of naringin (5) was accomplished by means of chemical evidence and comparison of its spectral features with literature data ${ }^{9}$. Acid hydrolysis of naringin followed by HPLC analysis employing a chiral detector afforded the aglycone 4',5,7-trihydroxyflavanone, Lrhamnose and D-glucose. The sugar moiety was determined to be neohesperidose (2-O- $\alpha$-Lrhamnopyranosyl-D-glucopyranose) by HMBC and NOESY spectra. Acetylation of $\mathbf{5}$ gave the hexaacetylated derivative 8.

So far, reports on the natural occurrence of $p$-hydroxystyrene and its glycosides is rare. While $p$-hydroxystyrene and its $\beta$-D-glucoside were isolated from Papaver somniferum in $1945,{ }^{10}$ the isolation of a few $p$-hydroxystyrene glycosides from ferns was described many years later, in 1985. ${ }^{2}$ Noteworthy, the disaccharide neohesperidose has been found in other ferns as the sugar moiety of $p$-hydroxystyrene glycosides while in our present collection it is attached to the flavanone naringenin.

\section{Effects of $E$. spathulatum constituents on the ovipositional behavior of $\boldsymbol{C}$. capitata}

The fruit fly C. capitata causes important economical damages in the north of Argentina. Substances that affect their behavior can be used in the development of pest control agents.

Crude extracts and bitter substances of E. spathulatum were tested to evaluate their effects on the ovipositional behavior of $C$. capitata.

The influence of chemical agents on the ovipositional response of the fruit fly Anastrepha suspensa (Loew) was studied by Szentesi et al. in 1979. ${ }^{11}$ As a part of their study, they evaluated the effect of naringin, and found that females did not respond differentially to plain or treated agar, except for the highest concentration tested $(0.01 M)$ in which females rejected treated agar.

Our quantitative results are described herein employing an oviposition index $\left(\mathrm{I}_{\mathrm{O}}=100 \mathrm{~T} / \mathrm{C}\right)$ calculated as the ratio of the number of eggs laid inside the treated substrate (T) and the ones laid inside the control substrate (C) expressed in \%. The results of this experiment are summarized in Table 1. Pair wise Tukey test indicated a significant difference in the preference for the control substrate compared with the substrate treated with $6 \mu \mathrm{g} / \mathrm{cm}^{2}$ of elaphoside-A and $14 \mu \mathrm{g} / \mathrm{cm}^{2}$ of ether or methanol extract. Naringin did not significantly affect the fruit fly behavior at the tested concentration $(P>0.05$ are considered not significant). 
Table 1. Oviposition index $\left(\mathrm{I}_{\mathrm{O}}\right)$ of crude extracts and bitter-tasting compounds isolated

\begin{tabular}{lllc}
\hline \multicolumn{1}{c}{ Sample } & $\begin{array}{c}\mathrm{N}^{\circ} \text { eggs laid on treated } \\
\text { substrate }(\mathrm{T})^{\mathrm{ab}}\end{array}$ & $\begin{array}{c}\mathrm{N}^{\circ} \text { eggs laid on non- } \\
\text { treated substrate }(\mathrm{C})^{\mathrm{ab}}\end{array}$ & $\mathrm{I}_{\mathrm{O}}=100 \mathrm{~T} / \mathrm{C}$ \\
\hline E. spathulatum (ether extract) & $271.7 \pm 68.9 \mathrm{aA}$ & $722.0 \pm 34.5 \mathrm{~dB}$ & 37.6 \\
E. spathulatum (methanol extract) & $399.0 \pm 91.4 \mathrm{acA}$ & $709.0 \pm 165.6 \mathrm{~dB}$ & 56.6 \\
elaphoside-A & $464.7 \pm 73.0 \mathrm{bcA}$ & $897.3 \pm 120.7 \mathrm{~dB}$ & 52.1 \\
naringin & $610.3 \pm 212.6 \mathrm{acA}$ & $774.3 \pm 157.2 \mathrm{dA}$ & 74.1 \\
\hline
\end{tabular}

a Means within a column or a row followed by the same letter (lower and upper case respectively) are not significantly different ( $P>0.05$, Tukey multiple range test).

${ }^{\mathrm{b}}$ Numbers represent mean $\pm \mathrm{SEM} ; \mathrm{n}=3$.

\section{Diet choice test}

When treated and control diets were presented to $C$. capitata adults, no significant differences were observed in their response. Treated diets contained $250 \mathrm{ppm}$ of extracts and bitter pure compounds obtained from E. spathulatum.

\section{Experimental Section}

General Procedures. For TLC detection, Godin reagent ${ }^{12}$ was used. For separation of mixtures an HPLC equipped with differential refractometer, a silica gel and a reverse phase C18 columns were employed. For separation of sugars a Shodex Rspak NH2P-50 4E column. Absolute configuration of sugars was determined using chiral detection in a Shodex OR-1 detector. The mixture $\mathrm{CH}_{2} \mathrm{Cl}_{2}-\mathrm{MeOH}$ (1:1) was used for separations with Sephadex LH-20. GC-MS spectra were obtained on a Hewlett Packard 6890 gas chromatograph with an HP-5973 mass selective detector. A capillary column $(30 \mathrm{~m}$ x $0.25 \mu \mathrm{m}$ i.d.) coated with phenyl methyl siloxane $(0.25 \mu \mathrm{m}$ film thickness) was used. IR spectra were recorded on a JASCO FT/IR-41. Ultraviolet spectra were measured in methanol on a SHIMADZU UV-160A spectrophotometer. NMR spectra were performed at 150 and $75 \mathrm{MHz}$ for ${ }^{13} \mathrm{C}$ and 600 and $300 \mathrm{MHz}$ for ${ }^{1} \mathrm{H}$ on a Varian UNITY 600 and Varian MERCURY 300, respectively. Optical rotations were measured on a JASCO DIP-1000 automatic digital polarimeter.

Plant material, extraction and isolation. Elaphoglossum spathulatum was collected in June of 2001 at Tiraxi, Jujuy province, Argentina. A voucher specimen (Muruaga 366) was deposited in the Herbarium of the Fundación Miguel Lillo, Tucumán, Argentina.

After being air-dried, the sterile fronds $(30 \mathrm{~g})$ were mechanically powdered and then successively extracted with ethyl ether and methanol.

The ether extract $(1.3 \mathrm{~g})$ was chromatographed on silica gel using a gradient of hexane-ethyl acetate as eluent. From this process VIII fractions were collected. From the first fraction $5 \mathrm{mg}$ of 
diploptene (3) crystallized as colorless needles. The qualitative composition of volatile constituents of fractions I to IV was determined by CG-MS, the following compounds being detected: Vitamin E, phytol, neophytadiene, stigmast-4-en-3-one, aspidinol, desaspidinol, 1(2,4,6-trihydroxyphenyl)-2-pentadecanone, 6,10,14-trimethyl-2-pentadecanone, and methyl arachidonate.

MPLC followed by HPLC of fraction V (50mg) yielded $\beta$-sitosterol (4 mg), ergost-5-en-3-ol $(1 \mathrm{mg})$ and stigmasterol $(1 \mathrm{mg})$, identified by their spectral features.

A portion $(3 \mathrm{~g})$ of the methanol extract $(5.5 \mathrm{~g})$ was repeatedly chromatographed on silica gel with $\mathrm{CHCl}_{3}-\mathrm{MeOH}$ mixtures, and Sephadex $\mathrm{LH}-20$, leading to the isolation of elaphoside-A (4, $37 \mathrm{mg}$ ) and naringin $(5,124 \mathrm{mg})$ respectively.

Elaphoside-A (4): amorphous solid, $[\alpha]_{\mathrm{D}}-20.2^{\circ}(\mathrm{MeOH}, c: 1.02)$, HR-FAB-MS $\mathrm{m} / \mathrm{z}$ : 467.1538 (calculated for $\mathrm{C}_{20} \mathrm{H}_{28} \mathrm{O}_{11} \mathrm{Na}$ : 467.1529), $\mathrm{UV} \lambda_{\max }(\mathrm{MeOH}) \mathrm{nm}(\log \varepsilon): 212.0$ (4.07), 255.0 (4.21), 287.6 sh. (3.42), 298.8 sh. (3.23), IR cm ${ }^{-1}: 3338,1628,1605,1509,1080,1044$, 905, ${ }^{1} \mathrm{H}-\mathrm{NMR}$ (600 MHz, methanol- $\mathrm{d}_{4}$ ) $\delta: 3.31-3.34$ (overlapping signals, H-2', H-4"'), 3.38 (t, $9.0 \mathrm{~Hz}, \mathrm{H}-3$ ' '), 3.64 (dd, 3.0, $7.8 \mathrm{~Hz}, \mathrm{H}-2$ '), 3.65-3.71 (overlapping signals, H-5' ', H-4'), 3-823.88 (overlapping signals, H-6', H-6', H-5'), 4.31 (t, 3.0, H-3'), 4.53 (d, 7.8, H-1 '), 5.11 (dd, $\left.0.9,10.8, \mathrm{H}-8_{\text {cis }}\right), 5.19$ ( $\left.d, 7.8, \mathrm{H}-1^{\prime}\right), 5.64$ (dd, 0.9, 17.4, H-8 $\left.8_{\text {trans }}\right), 6.66$ (dd, 10.8, 17.4, H-7), 7.04 (d, 8.4, H-2, H-6), 7.35 (d, 8.4, H-3, H-5), ${ }^{13} \mathrm{C}-\mathrm{NMR}$ (150 MHz, methanol-d 4 ) $8: 68.7$ (C-4'), 71.3 (C-2'), 75.4 (C-2'”), 77.9 (C-3'), 83.9 (C-3'), 100.2 (C-1'), 106.0 (C-1'”), 112.4 (C-8), 117.6 (C-2, C-6), 128.3 (C-3, C-5), 133.4 (C-4), 137.5 (C-7), 158.8 (C-1).

Methanolysis of elaphoside-A (4): A solution of $4(17.8 \mathrm{mg})$ and concentrated $\mathrm{H}_{2} \mathrm{SO}_{4}(20 \mu \mathrm{l})$ in $\mathrm{MeOH}(4 \mathrm{ml})$ was refluxed for 10 hours, cooled to room temperature, neutralized with a saturated $\mathrm{NaHCO}_{3}$ solution, and concentrated. The residue was diluted with water $(3 \mathrm{ml})$ and the mixture was extracted with $\mathrm{CHCl}_{3}(3 \times 3 \mathrm{ml})$. The combined organic extracts were dried and concentrated to give a phenol $(7,2 \mathrm{mg})$. The spectral data of this compound was in good agreement with data from literature ${ }^{8}$. The aqueous layer of the reaction mixture was concentrated. A solution of the residue and $\mathrm{Ac}_{2} \mathrm{O}(2 \mathrm{ml})$ in pyridine $(2 \mathrm{ml})$ was stirred at room temperature for 14 hours and concentrated. The residue was extracted with $\mathrm{CHCl}_{3}(5 \mathrm{ml})$ and the extract was concentrated to give a mixture. Separation of which by HPLC (column: WATERS 5C18-AR-II, mobile phase: $\mathrm{MeOH}-\mathrm{H}_{2} \mathrm{O} 1: 1 \mathrm{v} / \mathrm{v}, 1 \mathrm{ml} / \mathrm{min}$ ), afforded methyl 2,3,4,6-tetra-Oacetyl- $\alpha$-D-glucopyranoside $\left([\alpha]_{\mathrm{D}} 130.7\left[\mathrm{CHCl}_{3}, c: 1.37\right]\right)$ and methyl 2,3,4,6-tetra-O-acetyl- $\beta$ D-allopyranoside $\left([\alpha]_{\mathrm{D}}-30.0\left[\mathrm{CHCl}_{3}, c: 1.42\right]\right)$. Identification of these compounds was carried out by comparison of spectral data and specific rotations with those of authentic samples.

Acetylation of elaphoside-A (4): A mixture of $4(10.8 \mathrm{mg}), \mathrm{Ac}_{2} \mathrm{O}(0.5 \mathrm{ml})$ and pyridine $(0.5$ $\mathrm{ml})$ was stirred at room temperature for 8 hours and concentrated to give 6: $[\alpha]_{\mathrm{D}}-12.47\left(\mathrm{CHCl}_{3}\right.$, c: 0.89), FAB-MS m/z: $761(\mathrm{M}+\mathrm{Na}), 777(\mathrm{M}+\mathrm{K}), \mathrm{IR} \mathrm{cm}^{-1}:$ 1749, 1630, 1606, 1510, 907, 841, ${ }^{1} \mathrm{H}-\mathrm{NMR}\left(600 \mathrm{MHz}, \mathrm{CDCl}_{3}\right) \delta: 2.021,2.024,2.06,2.08,2.09,2.10,2.15$ (3H each, s, $\left.-\mathrm{OCOC}_{3}\right)$ $3.65(1 \mathrm{H}, d d d, 1.8,5.4,9.6 \mathrm{~Hz}, \mathrm{H}-5$ ' ') $4.02(1 \mathrm{H}, d d d, 2.4,5.4,9.6 \mathrm{~Hz}, \mathrm{H}-5$ '), $4.03(1 \mathrm{H}, d d, 1.8$, $\left.12.6 \mathrm{~Hz}, \mathrm{H}-6_{\mathrm{a}}{ }^{\prime}{ }^{\prime}\right), 4.16\left(1 \mathrm{H}, d d, 1.8,12.6 \mathrm{~Hz}, \mathrm{H}-6_{\mathrm{a}}{ }^{\prime}\right), 4.22\left(1 \mathrm{H}, d d, 5.4,12.6 \mathrm{~Hz}, \mathrm{H}-6_{\mathrm{b}}{ }^{\prime}\right), 4.23(1 \mathrm{H}$, $\left.d d, 5.4,12.6 \mathrm{~Hz}, \mathrm{H}-6_{\mathrm{b}}{ }^{\prime}\right), 4.34(1 \mathrm{H}, d, 7.8 \mathrm{~Hz}, \mathrm{H}-1$ '”), $4.58(1 \mathrm{H}, t, 2.4 \mathrm{~Hz}, \mathrm{H}-3$ '), $4.76(1 \mathrm{H}, d d$, 
3.0, 8.4 Hz, H-2'), 4.95 (1H, dd, 2.4, $10.2 \mathrm{~Hz}, \mathrm{H}-4$ '), 5.03 (1H, t, $7.8 \mathrm{~Hz}, \mathrm{H}-4$ '’), 5.10 (1H, dd, 7.8, $9.6 \mathrm{~Hz}, \mathrm{H}-2$ ' ') 5.18 (1H, dd, 0.6, $\left.10.8 \mathrm{~Hz}, \mathrm{H}-8_{\text {cis }}\right), 5.21(1 \mathrm{H}, t, 9.6 \mathrm{~Hz}, \mathrm{H}-3$ '’), 5.34 (1H, d, $\left.8.4 \mathrm{~Hz}, \mathrm{H}-1^{\prime}\right), 5.64$ (1H, dd, 0.6, $\left.18.0 \mathrm{~Hz}, \mathrm{H}-8_{\text {trans }}\right), 6.67(1 \mathrm{H}, d d, 10.8,18.0 \mathrm{~Hz}, \mathrm{H}-7), 6.98(1 \mathrm{H}$,

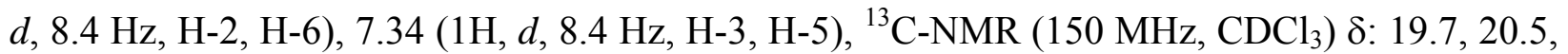
20.60, 20.63, 20.70, 20.74 (overlapping signals, -OCOCHH 3$) 61.8(\mathrm{C}-6$ '’), 62.2 (C-6'), 67.8 (C4'), 68.1 (C-4'’), 69.9 (C-5'), 70.4 (C-2'), 71.3 (C-2’’), 71.8 (C-5'’), 72.4 (C-3'’), 74.9 (C-3'), 96.8 (C-1'), 102.2 (C-1'’), 112.7 (C-8), 117.2 (C-2, C-6), 127.3 (C-3, C-5), 132.8 (C-4), 136.0 (C-7), 156.5 (C-1), 169.2, 169.3, 169.4, 169.8, 170.2, 170.6, 170.7 (overlapping signals, $\mathrm{C}=\mathrm{O}$ ).

Acid hydrolysis elaphoside-A (4): a mixture of $4(5 \mathrm{mg}), \mathrm{H}_{2} \mathrm{SO}_{4} 1 \mathrm{M}(1.2 \mathrm{ml})$ and dioxane $(1.2 \mathrm{ml})$ was heated under reflux and stirred for 3 hours. After cooling, it was diluted with water and passed through an ion exchange resin (column IRA-35) to eliminate the acid. The eluate was analyzed by HPLC. D-glucose and D-allose were detected. The spectral data of the aglycone $p$ hydroxystyrene (9) was in agreement with data from literature ${ }^{13}$.

Acid hydrolysis of naringin (5): it was performed as in the case of elaphoside-A to give naringenin (10) and a mixture of D-glucose and L-rhamnose. The spectral data of $\mathbf{1 0}$ was in good agreement with those reported on the literature ${ }^{14}$.

Acetylation of naringin (5): acetylation of this compound and subsequent purification of the acetylated product was performed as in the case of elaphoside-A. The reaction afforded $\mathbf{8}$ : amorphous solid, ${ }^{1} \mathrm{H}-\mathrm{NMR}\left(600 \mathrm{MHz}, \mathrm{CDCl}_{3}\right) \delta$ : $1.22\left(3 \mathrm{H}, d, 6.0 \mathrm{~Hz}, \mathrm{H}-6{ }^{\prime \prime}\right.$ '), $1.977,1.988$, 1.994, 2.04, 2.11, 2.14, 2.32, 2.380, 2.381 (3H each, s, -OCOC$\left.{ }_{3}\right), 2.75(1 \mathrm{H}, d d, 3.0,16.8 \mathrm{~Hz}$, $\left.\mathrm{H}-3_{\text {cis }}\right), 3.03$ (1H, dd, $\left.13.8,16.8 \mathrm{~Hz}, \mathrm{H}-3_{\text {trans }}\right), 3.88$ (1H, ddd, 3.0, 6.0, 9.6 Hz, H-5' '), 3.99 (1H, $t$, $9.6 \mathrm{~Hz}, \mathrm{H}-2$ '”), 4.05 (1H, dq, 6.0, $10.2 \mathrm{~Hz}, \mathrm{H}-5$ ' '), 4.14 (1H, dd, 3.0, $12.0 \mathrm{~Hz}, \mathrm{H}-6 \mathrm{a}$ "'), $4.22(1 \mathrm{H}$, $\left.d d, 6.0,12.0 \mathrm{~Hz}, \mathrm{H}-6_{\mathrm{b}}{ }^{\prime}{ }^{\prime}\right), 5.00-5.03$ (overlapping signals, $\mathrm{H}-1$ ' ' ', H-2', ', H-4 ' ' '), 5.06 (1H, $t, 9.6$ Hz, H-4' '), 5.12 (1H, d, 7.8 Hz, H-1'’), 5.16 (1H, dd, 3.0, $10.2 \mathrm{~Hz}, \mathrm{H}-3$ ', '), 5.33 (1H, t, 9.6 Hz, H-3', ), 5.47 (1H, dd, 3.0, $13.8 \mathrm{~Hz}, \mathrm{H}-2), 6.34$ (1H, d, $2.4 \mathrm{~Hz}, \mathrm{H}-8), 6.55$ (1H, d, $2.4 \mathrm{~Hz}, \mathrm{H}-6)$, $7.16\left(2 \mathrm{H}, d, 8.2 \mathrm{~Hz}, \mathrm{H}-3\right.$ ', H-5'), 7.46 (2H, d, 8.2 Hz, H-2', H-6'), ${ }^{13} \mathrm{C}-\mathrm{NMR}\left(150 \mathrm{MHz}, \mathrm{CDCl}_{3}\right)$ $\delta: 17.5$ (C-6"'), 20.50, 20.58, 20.68, 20.70, 20.9, 21.06, 21.11 (overlapping signals, -OCOCH${ }_{3}$ ), 45.1 (C-3), 61.8 (C-6'), 66.9 (C-5'’'), 68.2 (C-2'’'), 68.3 (C-3'’'), 70.0 (C-4'’'), 70.8 (C-4'’), 72.3 (C-5'), 74.1 (C-3'’), 76.6 (C-2'’), 79.2 (C-2), 98.1, 98.2 (C-1', C-1'’'), 102.3 (C-6), 106.0 (C-8), 109.6 (C-10), 122.1 (C-3', C-5'), 127.4 (C-2', C-6'), 135.6 (C-1'), 151.0 (C-4'), 151.9 (C9), 161.8 (C-7), 163.9 (C-5), 169.2, 169.3, 169.6, 169.7, 170.00, 170.05, 170.1, 170.4 (overlapping signals, $\mathrm{C}=\mathrm{O}), 188.6(\mathrm{C}-4)$.

Insects. A colony of $C$. capitata was initiated with pupae obtained from infested oranges from the Northwest of Argentina. Adults fed on a diet made of water and a mixture of sugar and yeast hydrolysate $(3: 1)$. They were maintained in a rearing room with a photoperiod $12 \mathrm{~L}: 12 \mathrm{D}$, at $24 \pm$ $2^{\circ} \mathrm{C}$ and $60 \pm 10 \%$ RH. $^{15}$

Bioassays. Ovipositional behavior: Oviposition substrates were prepared with a mixture of peach juice $(500 \mathrm{ml})$, agar ( 1 teaspoonful) and sodium benzoate ( 1 teaspoonful) as preservative. This 
agar solution was poured into cylindrical molds, allowed to gel, and finally sliced. Agar cylinders were then wrapped in film paper to avoid dehydration. The surface of the wrapped cylinders was pricked with a needle and treated with an acetone solution of the sample to be tested in order to deposit $6 \mu \mathrm{g} / \mathrm{cm}^{2}$ of pure compounds or $14 \mu \mathrm{g} / \mathrm{cm}^{2}$ of crude extracts. Control cylinders were treated with acetone and the solvent was then eliminated in vacuo. Three groups of C. capitata adults were selected from our laboratory colony. Each group, consisting of five male-female pairs, was placed in a small cage, covered with a voile. Two agar cylinders (sample and control) were placed on the voile. After 4 days, eggs were gently rinsed from the agar and counted. The experiment was conducted in 3 replicates.

Diet choice test: Treated diets were prepared by impregnating a 3:1 mixture of sugar and yeast hydrolysate with an acetone solution of the sample to be tested to obtain a final concentration of $250 \mathrm{ppm}$. Control diet was only impregnated with the solvent, which was then evaporated in vacuo. Two dishes, containing treated and control diets, were placed in each cage. 20 adult couples were released in each cage. After $10 \mathrm{~min}$ the landings of individuals on each diet were counted during a 2 hours period. This bioassay was made by triplicate.

Statistical Analysis. Results are reported as mean \pm SEM. Differences in the mean values were evaluated by analysis of variance (ANOVA). The Tukey test was used for all pair wise comparisons of groups. In all statistical analysis $P$ values $>0.05$ were considered not significant.

\section{Acknowledgments}

We thank Lic. Nora Muruaga for the identification of the plant material, Dr. T. Hashimoto and K. Yoshikawa from TBU, for helpful discussion. This work was supported by grants from the Agencia Nacional de Promoción Científica y Tecnológica (ANPCyT) and Consejo de Investigaciones de la Universidad Nacional de Tucumán (CIUNT). Work in Japan was supported by a Grant-in-Aid for Scientific Research from the Ministry of Education, Science, Sports, Culture and Technology of Japan.

\section{References}

1. Guantay, M. E.; Hernández de Terán, M. Lilloa 1995, 38, 73.

2. Murakami, T.; Tanaka, N. Progress in the Chemistry of Organic Natural Products, 54, Springer, Vienna, 1988.

3. Toyota, M.; Oiso, Y.; Asakawa, Y. Chem. Pharm. Bull. 2001, 49, 1567.

4. Toyota, M.; Oiso, Y.; Asakawa, Y. Chem. Pharm. Bull. 2002, 50, 508.

5. Asakawa, Y. In Progress in the Chemistry of Organic Natural Products; Springer: Vienna, 1982, Vol. 42. 
6. Asakawa, Y. Progress in the Chemistry of Organic Natural Products, 65, Springer, Vienna, 1995.

7. Shiojima, K.; Ageta, H. Chem. Pharm. Bull. 1990, 38, 347.

8. Bohlmann, F.; Fritz, U.; King, R. M. Phytochemistry 1979, 18, 1403.

9. Bock, K.; Pedersen, C.; Pedersen, H. Adv. Carbohydr. Chem. Biochem. 1976, 33,11.

10. Schmid, H.; Karrer, P. Helv. Chim. Acta 1945, 28, 722.

11. Szentesi, A.; Greany, P. D.; Chambers, D. L. Entomol. Exp. Appl. 1979, $26,227$.

12. Godin, P. Nature 1954, 174, 134.

13. Everhart, E. T.; Craig, C. J. J. Chem. Soc. Perkin Trans. 1991, 1, 1701.

14. Duddeck, H.; Snatzke, G.; Yemul S. S. Phytochemistry 1978, 17, 1369.

15. Tanaka, N.; Steiner, L. F.; Ohinata, K; Okamoto, R. J. Econ. Entomol. 1969, 62, 967. 